\title{
MANAGING THAI TELEVISION IN THE DIGITAL LANDSCAPE
}

\author{
Thitinan B. Common \\ Department of Mass Communication, Faculty of Communication Arts, Chulalongkorn University, Thailand
}

\begin{abstract}
Digital Disruption" has brought a dynamic effect upon television industries all over the world. Thailand's digital television industry is still in its infancy and the Thai broadcasting sector has been undergoing significant technological and structural change. Digitisation has transformed the Thai television industry in all areas, such as content creation, the production process, and distribution. Organisational administrators are at the heart of this transformation as they have a pivotal role as change leaders. This article aims to explore the changing face of Thailand's broadcasting landscape. It focuses on how digital convergence has added opportunities, as well as challenges and uncertainty to the business and its professionals. Built within the concept of television study and media management theory, the paper draws attention to the challenges in managing media works in the digital-cultural landscape and the ways managements address them. This paper explores organisational culture, management practices, and communication and leadership styles, as well as the way television managements in Thailand exploit digital media to empower their aspiring professionals.
\end{abstract}

Keywords: Television, Management, Digital, Convergence

\section{Introduction}

Compared with other areas of business management, Television Management has its unique characteristics. It is not only involved with administration and financial aspects, but specific skills and knowledge such as production skills, technology literacy, consumer insight, and media policy and regulations are also required. The broadcasting industry, as a technological-driven industry, has been constantly transformed in all areas due to technological change. While analogue television models are based on scarcity of channels and aimed at offering a product designed to reach a large cross-section audience, digitisation, on the other hand, has increased the number of media channels and altered the audience's behavior and market segmentation. Digital technology is considered as a 'disruptive technology', the term defined by Day \& Schoemaker (2000) as "science-based innovations that have the potential to create a new industry or transform an existing one"; this has brought tremendous upheaval upon the broadcasting industry all over the world, and not excluding Thailand.

April 2018 marked the fourth anniversary of the digital switch-over of Thailand's broadcasting. Thailand's digital television industry is still in its infancy stage. Reports of lay-offs in the Thai television industry are significant, and many digital television operators have been struggling and are still struggling financially in terms of support and revenue after four years of operation. Thai TV Co Ltd., one of Thailand's digital television licensees, terminated its broadcast and returned the license. It also filed a lawsuit against Thailand's broadcasting regulator, The National Broadcasting and Telecommunication Commission (NBTC), for its slow and inefficient management in the digital broadcasting transition. The case went to court and in March 2018, The Central Administrative Court ruled that NBTC had to return bank guarantees issued by Bangkok Bank for around Bt1.5 billion to Thai TV Co Ltd.

Thai television industry has experienced a complexity of media works and management due to 'digital disruption', which has brought about a dynamic effect in areas such as content creation, market segmentation, production and distribution. The central aim of this paper, Managing Thai Television in the Digital Landscape, is to explore the media ecology of the Thai digital broadcasting industry and the challenging issues in television 
management within the digital-cultural landscape. It also focuses on management practices such as organisational culture and leadership styles adopted by the executives in the Thai television industry.

This paper is organised in three parts. It begins with an overview of the digital switch-over and the changing landscape of broadcasting in Thailand. Opportunities and challenging issues in television management within the digital-cultural landscape are subsequently discussed. Finally, excerpts from my recent research project, Managing Television in the Digital Era, are contributed focusing around management practices such as organisational culture and leadership styles exploited by the Thai television executives.

\section{Overview of digital switch-over and the changing landscape of broadcasting in Thailand}

Prior to the digital-switch over, Thailand's broadcasting industry was an oligopoly. There were six free-to-air terrestrial television operators, namely Channel 3, Channel 5, Channel 7, Channel 11 (NBT), Channel 9 (MCOT) and ThaiPBS. The main players in Thailand's broadcasting industry were Channel 3 and Channel 7 , which won a lion's share of the audience ratings. A number of media production agencies acted as content providers, feeding media content for those main operators. These content providers also had their own television outlets on the digital satellite platform. However, the coverage was not large scale, and the audience size was not as extensive as that of the main established channels. The content providers and television operators there for depended on each other: the station operators relied on the content produced by big media production agencies such as GMM Grammy Public Company Limited, RS Vision Company Limited, and Workpoint Entertainment Public Company Limited; in return, the content providers also depended on the station platform to reach their target audiences.

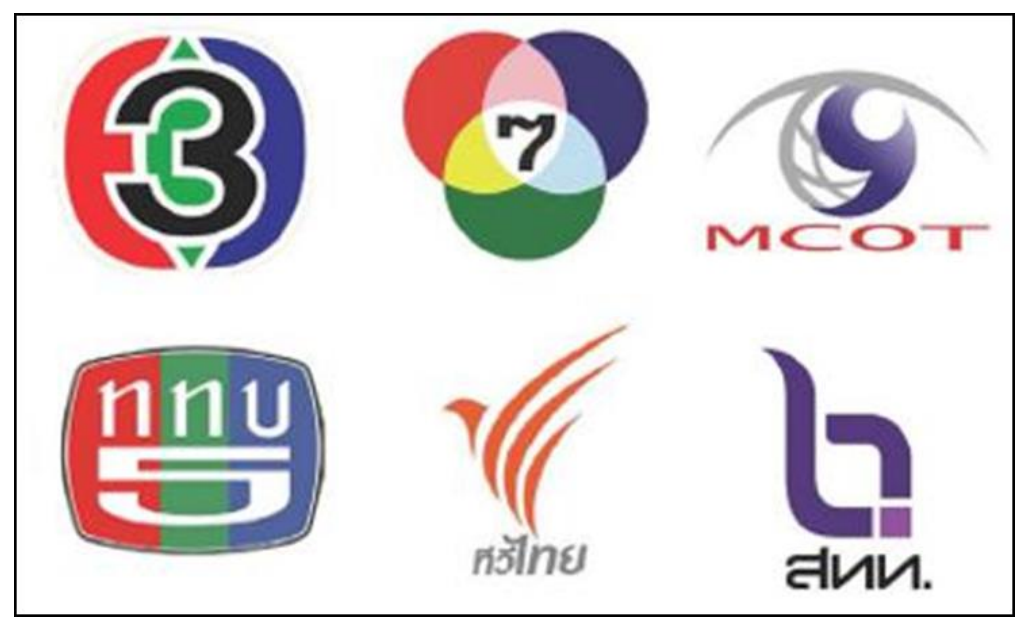

Figure 1: Logos of the six free-to-air terrestrial television operators in Thailand prior to the digital switch over. Top row from left to right are: Channel 3, Channel 7, and Channel 9 (MCOT). Bottom row from left to right

are: Channel 5, ThaiPBS, and Channel 11 (NBT). These operators have their own production departments which mainly focused on news production. They depended on the popular content provided by media production agencies. 

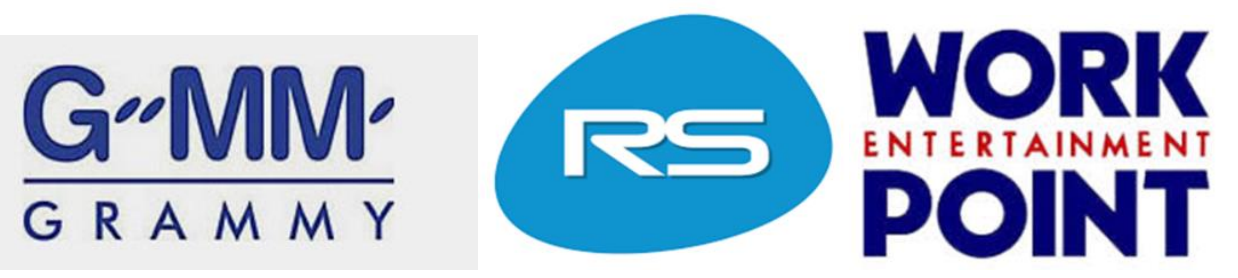

Figure 2: Three main content providers or media production companies in Thailand: GMM Grammy Public Company Limited, RS Vision Company Limited, and Workpoint Entertainment Public Company Limited. These media companies, along with other smaller agencies, are experienced in producing popular content such as drama, light entertainment, and game shows, which are popular genres amongst Thai viewers.

In 2014, The National Broadcasting and Telecommunication Commission (NBTC) - the independent ICT regulatory body of Thailand - granted 24 commercial digital TV channel licenses to winning bidders. This digital transformation is considered as a'big bang' force - a disruption which brought a destruction and reconfiguration of the new media ecology in the Thai television industry.

\section{Digital TV Auction Result :}

\begin{tabular}{|c|c|c|c|}
\hline Children & News & Variety SD & Variety HD \\
\hline $\begin{array}{l}13 \text { 3 Family } \\
14 \text { MCOT } \\
\text { Family } \\
15 \text { LOCA }\end{array}$ & $\begin{array}{l}16 \text { TNN24 } \\
17 \text { THV } \\
\text { (Thai TV) } \\
18 \text { new tv } \\
19 \text { Spring news } \\
20 \text { Bright TV } \\
21 \text { VoICE TV } \\
22 \text { Nation }\end{array}$ & $\begin{array}{ll}23 & \text { Workpoint tv } \\
24 & \text { True 4U } \\
25 & \text { G25 } \\
26 & \text { Now } \\
27 \text { CH } 8 \\
283 \text { SD } \\
29 \text { Mono } 29\end{array}$ & $\begin{array}{l}30 \text { MCOT HD } \\
31 \text { One HD } \\
32 \text { Thairath HD } \\
33 \text { HD } \\
34 \text { Amarin TV HD } \\
35 \text { CH } 7 \text { HD } \\
36 \text { 3G PPTV HD }\end{array}$ \\
\hline
\end{tabular}

Figure 3: Digital television results: NBTC granted 24 commercial category licenses to digital television bidders; these channels were launched in April 2014.

After the digital-switch over, Thailand's broadcasting emerged with 24 commercial television operators. These can be categorised in 3 tiers in terms of their origins.

\section{Digital terrestrial television (DTTV or DTT) in Thailand}

1. Tier 1: The analog-turned-digital operators

2. Tier 2: The content provider/satellite operators-turned-digital operators

3. Tier 3: The new digital operators

The Tier 1 analog-turned-digital operators are the operators of three of the main six established channels, namely Channel 3, Channel 7, and Channel 9 (MCOT); the other three established channels, Channel 5, Channel 11 (NBT), and ThaiPBS, were assigned Public Service Broadcasting licenses.

Tier 2, the content provider/satellite operators-turned-digital operators, are comprised of the main media production companies mentioned in figure 2: Workpoint TV operated by Workpoint Entertainment Public Company Limited, G25 and One HD operated by GMM Grammy Public Company Limited, andChannel 8 
operated by RS Vision Company Limited. In addition, this tier includes other channels operated by print media companies such as Thairath TV owned by the biggest newspaper publisher, Thairath Public Company Limited, and Amarin TV, which managed by Amarin Printing And Publishing Public Company Limited.

For tier 3, PPTV is the only player which has emerged as a new digital television operator. It is owned by Bangkok Media and Broadcasting Co., Ltd., a company managed by Bangkok Airways and Bangkok Hospital group.

Within the changing media ecology, Thai television has witnessed an increasing number of media players. This has brought about a turning point in the structural model of business competition. The content providers of Tier 2 which were previously business partners of the established analog-turned- digital operators (Tier 1), have become their business rivals. The Tier 2 content provider-turned-digital operators, specifically G25, One HD, Workpoint TV, and Channel 8, seem to be more adaptable. This is because they are experienced content producers who keep abreast of new technology and the evolving television market. These operators have their loyal target audiences and understand their viewers' changing behavior, tastes and trends. On the other hand, some of the operators in Tier 1 are catching up in the market since they have to struggle with the loss of content supplied from Tier 2. In this way, operators from Tier 1 have been hit hardest as they have had to compete with both the new comers and the rise in popularity of the internet and online media that has swamped the Thai media landscape.

The proliferation of digital television channels and the plethora of social media platforms has intensified the competitiveness in the Thai digital industry. The competition has taken place in many dimensions, such as competition for audiences, programming, and advertising revenue. The changing media ecology in the Thai television industry can be understood through Niche Theory. Derived from biological sciences, the term 'niche' was first used by Joseph Grinnell in 1924 to refer to animal ecology and describe how ecological objects and species fit together to form and function the organism (Vandermeer, 1972). Dimmick (2003) has applied Niche Theory in analysing media environment. He has proposed that Niche Theory postulated that media industries comprise of market niches just as ecological systems comprise of biological species. Therefore, the theory can be used to analyse competition among media agents for limited resources such as advertisers and audiences. In Thailand's digital media ecology, the television industry and market is an ecological system in which different types of agents are living together. These agents - station and platform owners, content producers, and advertisers, etc. - represent species of living bodies in the system with limited environmental resources.

In the digital media landscape, resources such as the audience number and content of media programmes remains the same; it is the number of media operators which has notably increased. This oversupply of media channels and platforms has brought a significant level of competition within the system. Media agents, television companies in particular, need to find strategies to reach their audiences and obtain advertising revenue. In order to survive in the changing media environment, media agents need to stay competitive by initiating programmes in order to improve their performance, as well as prepare their employees in adopting new essential skills to drive organisational success and outcomes. Change management, a discipline focusing on supporting individuals to successfully adopt change, is therefore central to managing television in the digital transition; as a change agent, television administrators play a prominent role in this transition.

\section{Opportunities and challenging issues in television management within the digital-cultural landscape}

In the digital media landscape, media consumption is being fragmented and spread across the media platform, which in turn contributes to the emergence of new patterns in media audience behavior. In order to survive, the industry and media organisations have to keep up with the rapidly evolving context of the media industry, such as marketing shifts and changing audience behavior (UGCs, Prosumer etc.). With corporations needing to adopt a new approach, theorganisational administrators are at the heart of this transformation as they have a pivotal role as change leaders. 
Digital disruption and media convergence has brought both positive opportunities and challenges in managing and administrating the television work. On the bright side, digital disruption is considered a positive force, bringing business opportunity to reach more audiences via a multiple platform. Digitisation and media convergence has offered a proliferation of digital television channels and online platforms. In this way, digital disruption has opened the doors to usher in new business opportunities in reaching target audiences; digital technology and innovation has also been regarded as a tool for new product development. This line of argument is evident in an emergence of a channels focusing on specific kinds of content and catering for segmented audiences - drama shows on Channel 8, teen drama series on G25, and the game show lover channel by Workpoint TV. Prior to the digital switch over, programmes such as dramas, series, and game shows were mainly scheduled during the post-watershed slot. But the digital media landscape has offered more channels and platforms for the production and air time of those genres which cater for segmented audiences. For example, after its launch on the digital platform, Channel 8 has produced and co-produced more television dramas, offering these in 'block programming' which suits the viewers' time schedule. Similarly, Workpoint TV, which is specialised in game show content, has produced more content and scheduled its popular shows during both night time and day time slots in order to cater for its fans' viewing patterns. The new media platforms such as online, social media, and mobile applications are also used to better reach the target audiences.

Findings from my research project building around dialogues with numerous television executives and professionals in Thailand also suggest that the majority of Thai television executives have considered digital technology as a dynamic tool for enhancing their business. However, television management is not only involved with non-human components such as production technology and financial management; it also engages with human aspects. In this way, one of the most challenging issues in managing television business is cultural and human management. The Thai television industry is currently facing a problem of a digital technology divide within the organisation. The younger professionals are more familiar with digital technology and new media production, while some older employees are still catching up with the changing technology. The substantial responsibility of television administrators is therefore to bridge the technological gap among the different generations of the workforce within the organisation, and to exploit digital media to empower their media work. Many television organisations have conducted workshops and training to help their staff become better equipped with a digital skillset. These workshops are normally facilitated by the younger workers - early adopters of technology - and are aimed at spreading technological knowhow and a positive attitude to the older generation. This in-house skillset training can be analysed in association with the theory of Diffusion of Innovations, which explains the process in which technology and innovation spread among members in a social system.

In his book Diffusion of Innovations, first published in 1962 and now in its fifth edition (2003), Rogers has proposed that there are four main factors that determine the spread of a new idea: innovation, communication channels, time, and a social system. Rogers has also defined types of adopters under five categories. These he terms innovators, early adopters, early majority, late majority, and laggards. Television organisation is a system comprising of staff members who possess different technological knowledge and digital skills. Workshop and training offered by the organisation is deemed as a communication channel to spread a digital mindset and skills, as an innovation, among the employees. As change leaders, television executives take the role of innovator, inspiring new ideas and a positive attitude regarding the advantages of digital technology across the organisational system. The younger staff, as change agents more familiar with digital technology, are early adopters who facilitate the spread of these ideas and attitudes, and encourage other workers as part of a social system to learn and practice in order to acquire digital skills for self-reliance. The process of innovation diffusion depends on human resources. This in-house training is therefore one of the human management strategies aimed at preparing the organisational workforce to work more effectively within the complex media environment. The ultimate purpose of this innovation diffusion management is to enhance the competency of employees - who represent the most valuable asset for managing television in the digital landscape. 


\section{Change Management: Organisational culture and leadership styles}

The process of new technology implementation always takes time; it often causes resistance, and can be inevitably stressful. The effect and process can also cause a decrease in short term job satisfaction. The change management approach plays an important role in easing this tension and creating an even pace of change, and organisational culture and leadership style is considered an important tool of change management. This part of the paper, derived from excerpts of my research project Management of Thai Television in the Digital Era, explores organistional culture and leadership style exploited by the Thai television executives in administering their work during the digital transition.

Culture is a shared belief, value, and practice among the members in the institution. Organisational culture is essential for unifying the organisation as a system where individuals work together, and it decides the direction for the functioning of the organisation. According to Handy (cited in Block, 2001), corporate culture can be classified into four types: Power Culture, Role Culture, Task Culture and Person Culture. Power Culture can be symbolised as a web, a corporate culture with a concentration of power. In this culture, the organisational manager represents a spider whose power is spread out like a network from the centre to the rest of the organisation.

The Role Culture symbolically resembles a group of Greek pillars. In this organisational culture, a company is comprised of pillars representing sections and departments, each with their expertise in division of work. In the Role Culture, the organisational administrators are positioned on the top of the roof acting as conductors with a bureaucratic and top-down management style.

The Task Culture is a teamwork-oriented and project driven culture which can be likened to a net model. Each team and project represents strands that unify and structure the net or organisation. In this team culture, management plays a facilitator role, providing financial support and resource management. This organisational culture is considered as flexible and suitable with media work, and it has been said that the BBC has adopted this cultural structure.

The Person Culture is an unusual style. It is a loose cluster of individuals with unique skills and expertise. This culture puts people above the organisation; however, there is still a structure to serve and assist the individual.

Applying Handy's four power structure in analysing the culture of the Thai broadcasting industry, it can be seen that in principal, every organisation has adopted the Role Culture as a core organisational structure. This is because the broadcasting industry involves large scale and complex work which needs a clear role and job definition, division of work, and systematic management. In this way, the Greek temple model is said to be the backbone that underpins every company's structure.

However, through dialogues with executives from the Thai television industry, it has been suggested that in practice the Task Culture has also been adopted to a certain extent within many organisations. Television work has its unique characteristics, and is involved with artistic aspects and creativity. Consequently, television professionals sometimes need to work in their own space, a space which allows freedom and flexibility. Management therefore embraces the Task Culturein its administration with regards to content creation and production work. This project-driven culture of task role allows the team to work with freedom in adecentralised environment.

There is no occurrence of the Person Model cultural structure in Thai broadcasting organisation. However, it's worth noting that the PowerCulture is also exploited regarding important and urgent issues. The decision will be made by the executive of the highest position in the organisation. The Power Culture is actually a pivotal culture that has been dominating the style of management in Thai broadcasting industry, and it's said to have worked well, with evidence of success in two established free-to-air channels, namely channel 3 and channel 7. 
Leadership style is also another key factor worth considering. While management is associated with decisionmaking, planning, and controlling, leadership involves communication and the process of social influence. Rensis Likert (cited in Dainton and Zelley, 2011) has suggested four leadership style approaches: Exploitive Authoritative, Benevolent Authoritative, Consultative Leadership, and Participative Leadership, concluding that the fourth approach -Participative Leadership - isthe most successful one, being that which produces more effective outcome and productivity.

The Exploitive Authoritative leadership style is based on fear and threat. It operates with one-way communication, and decision-making is centralised. Benevolent Authoritative is a leadership style which is based on rewards. The decision-making and communication is still one-way, but with some delegation. Consultative Leadership is based on appropriate rewards. It uses two-way communication, butwith limited upwards communication. The decision-making in this approach is decentralised, but still limited. Participative Leadership revolves around group participation. It uses two-way communication with a decentralised decisionmaking style.

Applying Likert's four styles of leadership in analysing the style used among the Thai television executives, it can be seen that no organisation adopted a single approach of leadership style. The executives instead use a mixed approach, as different operating units suit different types of management and leadership style. The executives with a traditional perspective have suggested that they used a mixture of the four systems depending on the nature of work in each division, while the executives with more modern outlook have maintained that they prefer to shift between the third and fourth approaches.

\section{Conclusion and Discussion}

Television, as an ever-evolving industry, has long been a leading medium and popular entertainment platform in Thailand. In the changing landscape of media ecology, traditional television is facing competition from social media in the form of Facebook, YouTube, LineTV, and video streaming such as NetFlix. As Caspi (cited in Lehman-Wilzigand Cohen-Avigdor,2004) has pointed out, every medium has four stages of its life-cycle. The first stage is an inauguration period in which the medium is initiated in the society. It is then followed by the institutionalisation stage of the process in which the medium is developed and popularised as an institution in the society. The medium will subsequently face challenges from the popularity of new media and will have to compete in order to keep its place: this is referred to as the defensive stage. Last is the adaptation stage, where, in order to survive, the medium needs to adapt within the new media environment. In this final stage, there are three ways of adjustment - adaptation, convergence, and obsolescence. Television in Thailand had its inauguration stage afterWorld War II, and as one of the most important cultural institutions in the Thai society subsequently went through its golden 'institutionalisation' age. It is now in a challenging period of defending and adapting itself in the digital media landscape, and television management plays a pivotal role in this stage of television's life-cycle.

To conclude, this paper is built around the premise that the television industry is a technologically driven industry. Digitisation and the internet as disruptive technology have brought tremendous upheaval, and following the digital switch over the Thai television industry has undergone changes such as organisational and business structural change, market shifts and complex audience segmentation.

Christensen and Overdorf (2000) have suggested that disruptive technology can bring positive change as well as chaos. In this way, in order to stay ahead in this competitive environment, corporations need to take digital disruption as a positive and powerful force in managing technology and innovation in the organisation. This is because innovation, as Dougherty (2006) has claimed, is a small unit of technology which has a powerful impact to drive change in the organisation. In addition, as managing television involves both human and non-human aspects, management has a role as a change leader to employ digital technology as a disruptive force to mobilise and drive the organisation. 
Technological change is a pivotal force of progress, but at the same time it poses great challenges. The big challenge for Thai television administrators is not only at the micro-level of the organisational management strategy. As well as such micro-level issues as questions about how to bridge the technological gap between resource people in different generation or how to exploit technological innovation and inspire change in the organisation for the maximum outcome or profit, the industry is also facing challenges at the macro-level of the political-economy of the media production industry. The daunting challenge which lies here for all Thai television professionals is about how to prevail in this changing media ecology, and, at the same time, how to still maintain the creative and production value of television as an art form which continues to play a crucial role in Thai culture and society.

\section{References}

Block, P., 2001, Managing in the media (Oxford: Focal Press).

Christensen, C. M., and Overdorf, M., 2000, Meeting the challenge of disruptive innovation.

Harvard Business Review, March/April, 67-76.

Dainton, M. \&Zelley, E., 2011, Applying Communication theory for professional life (London: Sage).

Day, G.S., \&Schoemaker, P.J.H., 2000, Wharton on managing emerging technologies (New York,

NY: Wiley).

Dimmick, W.J. , 2003, Media Competition and Coexistence: The Theory of the Niche (Mahwah, NJ:

Erlbaum).

Dougherty, D., 2006. Organising for innovation for 21th century. In: The Sage handbook of

organisation studies (pp.598-617), Edited by S.R. Clegg, C. Hardy, T.B. Lawrence, and W.R. Nord (London: Sage).

Rogers, E., 2003. Diffusion of innovations: Fifth Edition (New York: free Press).

\section{Internet Sources}

Lehman-Wilzig, S. and Cohen-Avigdor, N. ,2004, The natural life cycle of new media evolution Inter-media struggle for survival in the internet age Date of access: 20/02/2018. https://www.journals.sagepub.com/doi/abs/10.1177/146144804042524

Vandermeer, J., 1972, Niche Theory, Date of access: 20/02/2018. https://www.annualreviews.org/doi/pdf/10.1146/annurev.es.03.110172.000543 